\title{
RELATORIOS
}

\section{ENSINO DA NEUROLOGIA}

\author{
Paulo Pinto Pupo \\ JORGE ARMBRUST-FigueIREDO
}

$\mathrm{Na}$ feitura dêste relatório, do qual fomos incumbidos pela Academia Brasileira de Neurologia na reunião de Curitiba, em julho de 1963, procuramos colher dados que permitissem uma visão panorâmica de como é atualmente o ensino de Neurologia nas diversas escolas médicas do mundo e assinalar as principais informações obtidas na revisão da literatura sôbre o assunto.

Para tal fim, organizamos um questionário que foi enviado a 29 escolas médicas do Brasil, 19 da América do Sul, 34 da América do Norte, 62 da Europa e 14 da Ásia e da Austrália. Ésse questionário constou de duas partes principais: (a) ensino para os alunos do curso de graduação; (b) ensino de pós-graduação para formação de especialistas e pesquisadores em Neurologia.

$\mathrm{Na}$ primeira parte indagamos: em que ano letivo é ensinada a Neurologia; qual a correlação entre o curso de clínica neurológica e os cursos básicos correlatos (neuranatomia, neurofisiologia, neurofarmacologia e neuropatologia); qual a duração do ensino teórico e prático e se êste é feito em enfermaria e/ou em ambulatórios; qual a relação entre o número de estudantes e o de leitos para Neurologia e do pessoal docente habilitado, respectivamente; se os alunos assistem reuniões clínicas e clínico-patológicas e se são realizadas reuniões conjuntas com a neurocirurgia. Na segunda parte perguntamos: se no ensino de pós-graduação há regime de internato; se há necessidade de um estágio prévio em medicina interna; se a Neurologia constitui departamento autônomo ou se funciona em conjunto com a Clinica médica, com a Psiquiatria ou com a Neurocirurgia; se o residente passa

Relatório apresentado ao $1^{\circ}$ Congresso Brasileiro de Neurología (Ribeirão Prēto SP, 26 a 31 de julho de 1964) em mesa redonda na qual tomaram parte o Prof. Deolindo Couto (Rio de Janeiro, GB), o Prof. Elyseu Paglioli (Pôrto Alegre, RS), o Prof. Jorge Armbrust-Figueiredo (Ribeirāo Prêto, SP), o Prof. José Geraldo Albernaz (Belo Horizonte, MG), o Prof. José Ribe Portugal (Rio de Janeiro, GB), o Prof. Manoel Caetano de Barros (Recife, PE), o Prof. Oswaldo Freitas Julião (Sãn Paulo, SP), o Prof. Oswaldo Lange (São Paulo, SP), o Prof. Paulino W. Longo (São Paulo, SP) e o Prof. Paulo Pinto Pupo (São Paulo, SP), Tomou parte também, como convidado, o Prof. Helio Lemmi (Professor assistente na University of Tennessee Medical School, U.S.A.). 
obrigatỏriamente por estágios em neurocirurgia, neuropatologia, neuropediatria e psiquiatria; se existe interrelação funcional da Neurologia com outros serviços, tais como neurocirurgia, pediatria, oftalmologia, reabilitação, psiquiatria e patologia; qual o tempo mínimo exigido para o curso de pós-graduação em Neurologia e se há necessidade de provas de suficiência ao seu término.

\section{ENSINO DA NEUROLOGIA NO CURSO MÉDICO}

$\mathrm{Na}$ revisão da literatura sôbre o ensino da Neurologia no curso médico encontramos dados recentes quase que apenas em relação a equipes de trabalhc norte-americanos.

O ensino da Neurologia e o exercício da clínica neurológica nos Estados Unidos da América do Norte, na década de 1930 e até os anos de após guerra, sofreram análises muito pessimistas de preeminentes personalidades dessa época e dos especialistas da geração subseqüente (Riley, 1933; Wilson e Rupp, 1947; Nielsen, 1947; Schalier, 1947; Macley, 1947; os neurologistas estavam, então perdendo progressivamente seus doentes para os psiquiatras, psicanalistas e, ulteriormente, para os neurocirurgiões. Bailey (1942 e 1946) cita, inclusive, Ramsay-Hunt (1934) e Lhermitte (1933) que externaram a mesma opinião em relação ao que ocorria na Inglaterra e na França. Também a neurocirurgia estava em situação precária, exercida por neurocirurgiões sem a necessária preparação neurológica (Bucy, 1940; Bailey, 1946). Assim, os neurologistas derivavam suas atividades para outros setores da medicina: os que possuiam doentes neuróticos e psicóticos em suas clínicas privadas passavam a se dedicar mais a êles e a estudar os seus problemas; os que perseveravam na Neurologia pura, dirigiam seus estudos para o campo das pesquisas em neuranatomia e neurofisiologia. Tal situação resultava no desprestigio da Neurologia clínica. Paralelamente, não progrediu o ensino da Neurologia; ficou patente a carência do pessoal docente, houve decréscimo do número de candidatos aos títulos de especialista em Neurologia reconhecidos pela American Medical Association (Bailey, 1946). Os alunos passaram a não se interessar pela Clínica Neurológica e, em geral, eram mal informados a respeito da Neurologia como especialidade e ignoravam os progressos registrados nos últimos anos (Poser, 1960). Os dados estatísticos apresentados nos relatórios de Viets (1937), Greg (cit. por Bailey, 1943) Riley (1946) e Pollock (1949) demonstram a carência de ensino da Neurologia naquela época nas escolas norte-americanas: em poucas delas a Neurologia era ensinada independentemente da Psiquiatria, da Clínica médica ou da Neurocirurgia; o número de docentes era restrito e a distribuição de recursos para o ensino muito heterogênea; a grande maioria dos departamentos de Neurologia concentrava-se na costa atlântica norte do país.

Contra êste estado de coisas insurgiram-se os neurologistas que se achavam em evidência no após guerra, premidos pelo aumento considerável de pacientes neurológicos. Foram realizados inquéritos para avaliação dos neurologistas disponíveis, organizados programas para o ensino sistematizado da Neurologia, que passou a ser ministrado em departamentos independentes 
nas escolas médicas, foi incentivado o estabelecimento de residências em hospitais com a finalidade de preparar novos especialistas e novos membros para o corpo docente das escolas, foram efetivadas campanhas para o esclarecimento do público e dos podêres governamentais sôbre os acentuados progressos feitos pela Neurologia, visando angariar fundos para a construção de institutos e para programas de reabilitação dos mutilados de guerra. Papel relevante foi desempenhado pelas organizações hospitalares e de seguros dos veteranos (Bailey, 1947). O inquérito realizado por Bailey, em 1949, já oferece visão menos pessimista do cenário neurológico: questionários enviados a 850 especialistas aprovados em Neurologia, Psiquiatria, Neurocirurgia ou em mais de uma destas especialidades mereceram 521 respostas, mostrando que a Neurologia constituia especialidade bastante procurada e exercida com entusiasmo; que a idade média daquêles que a exerciam era de 45 anos, que eram indivíduos ainda muito ativos e ocupando cargos de destaque no meio médico em que viviam; o número de hospitais com serviços credenciados em pós-graduação de Neurologia aumentou substancialmente. O relatório de Poser, em 1960, relativo ao decênio seguinte, confirmou êstes dados, mostrando o aumento do número de residências aprovadas em hospitais com ensino pós-graduado em Neurologia. Contudo, a demanda de neurologistas permanecia grande e a sua distribuição geográfica continuava heterogênea.

A partir dessa época o ensino da Neurologia passou a ser encarado com interêsse todo especial. Wolff (1949) salientou a necessidade do ensino intensivo, coordenado com a neuranatomia e neuropatologia e com o ensino nas enfermarias de medicina interna. De Jong (1951) também advogou o ensino dos conhecimentos neurológicos paralelamente ao ensino da neuranatomia, neurofisiologia e neuropatologia, ressaltando que os conhecimentos de semiologia e o raciocínio para o diagnóstico neurológico devem ser apresentados ao aluno de maneira simples e atraente, entrosados intimamente com os conhecimentos da clínica e da patologia médicas, salientando sua intima correlação e interdependência. Os relatórios e as discussões na reunião promovida pelo National Advisory Neurological Diseases and Blindness Council e pelo National Institute of Neurological Diseases and Blindness, em 1956, na qual tomaram parte A. B. Baker, Pearce Bailey, H. H. Merrit, R. de Jong, Fances Foster, O. H. Lowry, A. S. Severinghaus, G. H. Seger, G. Asgaard, J. O'Leary, R. Richter, Augustus Rose e A. L. Sahs mostram êsse interêsse. Destas discussões sobressai a afirmaçoã de que são inseparáveis o Serviço de Neurologia-Internato de Pós-Graduação e o ensino no curso médico; foi salientada a absoluta necessidade de criação de serviços bem organizados, funcionando com pessoal docente em regime de tempo integral para obter ensino satisfatório. Os alunos devem viver os problemas da evolução de cada paciente; os jovens residentes desempenham papel fundamental neste tipo de ensino, desde que existe maior intimidade nas relações estudante. residente que nas dos alunos com docentes mais idosos ou com os que ocupam posições hieràrquicamente elevadas. Essa interrelação é útil tanto para o aluno quanto para o residente. Dai ser preferivel a uma escola médica ter maior número de residentes que aumentar o número do pessoal docente permanente. 
Em tôda essa campanha - empreendida para melhorar a situação dos neurologistas como especialistas, para lhes dar maiores recursos na pesquisa, para prover a nação de maior número de médicos capazes de enfrentar os problemas da legião de mutilados de guerra - partiram os pioneiros do princípio de que o sistema nervoso é o sistema central do organismo, o mais importante, aquêle do qual dependem todos os outros sistemas da economia; por isso deve ocupar posição relevante na educação médica, como já apregoavam Bernard Sachs (Congresso Neurológico de Berna, 1931) e Monrad Krohn (Congresso Neurológico de Paris, 1950). As conseqüências desta campanha foram esplêndidas. A Neurologia, que em determinada época fôra uma especialidade dedicada aos diagnósticos brilhantes, mas estática em seus propósitos, tornou-se essencialmente dinâmica, procurando diagnósticos mais consentâneos com os problemas da patologia geral. Tais diagnósticos, embora nem sempre tão precisos do ponto de vista topográfico, permitiram melhor e mais precoce intervenção do médico em benefício de seus pacientes. A terapêutica clínica e o tratamento cirúrgico, bem como os métodos de reabilitação física e mental, possibilitaram extraordinário desenvolvimento da Neurologia.

\section{RESUltados DO INQUÉRITO REALIZADO}

Nos Estados Unidos da América do Norte - Obtivemos informações de 24 escolas médicas mas baseamos nossa análise em apenas 20 , desde que as demais não forneceram dados suficientes para uma avaliação precisa do desenvolvimento dos cursos normais de Neurologia (1. University of California at Los Angeles; 2. University of Southern California; 3. Georgetown University; 4. Cornell University; 5. University of Cincinatti; 6. Ohio State University; 7. New York University; 8. University of Michigan; 9. University of Wisconsin; 10. University of Minnesota; 11. University of Kansas; 12. Boston University; 13. University of California at San Francisco; 14. Harvard University; 15. Columbia University; 16. College of Medical Evangelists; 17. George Washington University; 18. Temple University; 19. Union Univ., Albany College of Medicine; 20. Duke University):

(a) O currículo do curso médico desenvolve-se em 4 anos nas 20 escolas.

(b) Tôdas mantêm cursos de neuranatomia e neurofisiologia, sendo que em $13(1,2,3,4,5,7,8,12,13,14,15,18,19)$ tais cursos são integrados com o departamento de Neurologia, as aulas sendo ministradas com a colaboração de neurologistas; em 4 destas $(3,8,14,17)$ o departamento de Neurologia é o responsável pelos cursos de neuranatomia e/ou neurofisiologia. Em 3 escolas $(6,16$, 17) tais cursos são dados independentemente do departamento de Neurologia. Das demais 4 escolas $(9,10,11,20)$ não obtivemos informações.

(c) No ensino da clínica neurológica procuramos verificar a situação do curso de semiologia. Em 11 das escolas $(1,2,3,4,5,8,13,15,16,19,20)$ são realizados cursos de "Introdução à Neurologia", sendo que em 10 no segundo ano do curriculo e em uma (8) no terceiro ano; as restantes 9 escolas não forneceram dados precisos. Vale a pena salientar que êsses cursos, na maioria das vêzes, incluem, não apenas a semiologia neurológica, mas também a correlação da neuranatomia e neurofisiologia com a clínica e, ainda, fundamentos de neuropatologia. o tempo dedicado a êste estudo varia de 17 a 36 horas, sendo a duração média de 22 horas anuais, distribuidas em aulas práticas e demonstrações.

(d) O curso de clínica neurológica desenvolve-se nos terceiro e quarto anos. As 20 escolas mantêm cursos no terceiro ano, nos quais os estudantes assistem aulas teóricas e recebem instruçāo prática nas enfermarias. A duração dêstes cursos é muito variável mas é nítido o predominio do ensino prático soobre o teó- 
rico; a duração média do curso teórico é de 17 horas, ao passo que a do curso prático é de 120 horas. A permanência dos estudantes nas enfermarias também varia de acôrdo com a escola considerada: em $12(1,2,3,5,7,8,9,10,13,14,17$, 18) os estudantes permanecem de 2 a 10 semanas nas enfermarias, desempenhando certa atividade assistencial. Em 13 escolas $(2,3,4,5,7,10,12,13,14,16$, $17,18,19)$, além dos cursos teórico e prático, os alunos assistem conferências clínico-patológicas, realizadas 2 a 4 vêzes por mês. O curso no quarto ano tem caráter obrigatório em 16 escolas e é eletivo nas outras 4 (7, 9, 12, 13). Tem caráter predominantemente prático, sendo que em apenas 3 escolas $(5,11,15)$ são realizadas aulas teóricas, com duraçāo média total de 16 horas. Os estudantes freqüentam as enfermarias em grupos de 5 a 8 , por períodos variáveis de 2 a 4 semanas, sob a orientação direta dos residentes e docentes. Em 11 escolas $(3,6,7,8,10,11,14,16,17,18,19)$ os estudantes freqüentam o ambulatório por periodos que variam de 3 dias a 3 mêses, com tempo médio de 3 semanas.

(e) Em 15 escolas $(2,3,5,7,8,9,10,12,13,14,15,17,18,19,20)$ o departamento de Neurologia é independente, autônomo; um dêstes (17) engloba o serviço de neurocirurgia. Em 4 escolas $(1,4,6,11)$ a Neurologia integra o departamento de Medicina interna e, em uma (16), faz parte do departamento de NeuroPsiquiatria.

(f) Em 9 escolas $(1,2,3,4,8,10,14,15,17)$ o número de leitos para pacientes neurológicos perfaz o total de 534, com média de 59.

(g) O número de estudantes por cada escola é variável. Com referência Ao ano letivo de 1962-63 encontramos o total de 1860 alunos distribuidos no terceiro ano de 18 escolas $(1,2,3,4,5,8,9,10,11,12,13,14,15,16,17,18,19,20)$ com a média de 103 alunos por escola.

(h) Em relação ao número de docentes encarregados dos cursos de Neurologìa, não nos foi possivel obter dados pormenorizados em relação à maioria das escolas. Algumas das respostas que obtivemos consideravam todos os docentes participantes dos cursos, inclusive os "visiting neurologists"; outras referiam-se apenas à composição oficial do "staff" departamental; em outras eram citados todos os integrantes do departamento, sem maiores esclarecimentos.

(i) Chamou-nos a atenção a pouca referēncia ao pessoal docente que trabalha em regime de tempo integral nas informações recebidas. Dos "full professors" apenas um trabalha neste regime e, segundo os dados que nos foram oferecidos, o total do pessoal em dedicação plena ao ensino e à pesquisa é de três por cento.

Na Europa - Informações sôbre a organização do ensino da Neurologia na Europa foram recebidas de 11 paises num total de 23 escolas. $O$ presente estudo baseou-se, contudo, nos dados de 20 escolas (21. Universitẻ de Paris, França; 22. Université de Louvain, Bélgica; 23. Université Libre de Bruxelles, Bélgica; 24. Université de Liège, Bélgica; 25. University of Oslo, Noruega; 26. Zürich Universität, Suiça; 27. Basel Universität, Suiça; 28. University of Oxford, Inglaterra; 29. Universitá di Genova, Itália; 30. Universitá di Milano, Itália; 31. Slovenskej University, Checoslováquia; 32. Hamburg Universität, Alemanha; 33. Polskie Towarzistwo Neurologiczne, Polônia; 34. Universiteit Leiden, Holanda; 35. Universität Freiburg, Alemanha; 36. Universität Bonn, Alemanha; 37. Universität Münster, Alemanha; 38. Humboldt Universität, Alemanha; 39. Institul de Neurologie I. P. Pavlov, Rumānia; 40. Facultad de Medicina de Barcelona, Espanha):

(a) A duração do curso médico não é a mesma em tôdas as escolas: assim, uma (23) tem o curriculo desenvolvido em 5 anos, $4(35,36,37,38)$ em 5 e meio anos, $9(21,28,29,30,31,32,34,39,40)$ em 6 anos, $2(25,26)$ em 6 e meio anos, $4(22,24,27,33)$ em 7 anos. A organização dos cursos também é heterogênea, sendo que em algumas o curriculo é rígido, em outras o ensino das ciências básicas é feito independentemente das matérias clínicas e em outras, ainda, o curso de matérias obrigatórias compreende 5 anos e os cursos optativos mais 1 ou 2 anos. 
(b) O ensino da neuranatomia e da neurofisiologia nāo tem qualquer relação com o departamento de Neurologia em 19 das escolas; apenas em uma (35) a cátedra de Neurologia é responsável pelo ensino da neurofisiologia.

(e) O ensino de Neurologia não obedece a sistematização regular em várias das escolas, tornando difícil a comparação dos métodos aplicados. Assim, a Neurologia não faz parte do currículo médico obrigatório em 2 escolas $(23,40)$; em outra (28) todo o ensino da Neurologia se faz em apenas um mês, de modo intensivo; em outra (32) o curso não tem previsão fixa, embora em geral seja desenvolvido no segundo ano clínico; em 6 outras $(29,30,35,36,37, \quad 38)$ a Neurologia é ensinada juntamente com a Psiquiatria, não havendo individualização de cada matéria; em uma (24) o curso é dado dentro do programa de Clínica Médica. A avaliação do curso de semiologia torna-se, pois, muito dificil, diante da variedade de organização de currículos; em apenas $3(24,25,32)$ nos foi possivel identificar o ensino da propedêutica neurológica, cuja duração varia entre 4 e 24 horas anuais.

(a) O curso de clinica neurológica tem características e duração diversas: na Universidade de Oxford (Inglaterra) todo o curso é dado em apenas um mês, com dedicação exclusiva do aluno; na Universidade de Hamburg (Alemanha), o curso não tem distribuição e duração fixas, variando de ano para ano; nas Universidades de Genova e Milano (Itália) e de Berlin, Bonn e Münster (Alemanha) a Neurologia e a Psiquiatria são ensinadas em um mesmo departamento. A situação do curso de clínica neurológica varia muito dentro dos currículos; em $4(21,26,28,31)$ o curso é dado no segundo ano clínico e em uma (33) no primeiro ano. Sua duração também é varável: em 12 escolas o curso se desenvolve durante um ano; em uma (34) durante 2 anos; em 2 (22, 25) durante 3 anos; em $2(24,27)$ durante 4 anos. A distribuição de aulas teóricas e práticas do curso de Neurologia é diversa daquela encontrada nas escolas norte-americanas: o curso teórico é mais extenso, com número de aulas maior, ocupando de 60 a $35 \%$ do tempo total dedicado ao ensino. Em geral são utilizados sòmente doentes internados; as aulas constam, geralmente, de demonstraçōes clínicas, os estudantes não desempenhando atividade assistencial. O número de reuniões clínico-patológicas é restrito a algumas escolas. A utilização de ambulatório para o aprendizado é reduzida; apenas em 5 escolas $(24,25,28,32,33)$ os estudantes participam destas atividades.

(e) Das 20 escolas consideradas, 10 possuem departamento de Neurologia autônomo, sendo que em uma (22) a neurocirurgia lhe é agregada; em 6 (29, 30, 35, 36, 37, 38), a Neurologia faz parte do departamento de Neuro-Psiquiatria; em 2 (23, 24) está integrada no departamento de Clínica Médica; em uma (40) não existe cátedra de Neurologia.

(f) O número de leitos em 8 escolas $(22,24,25,27,29,33,35,39)$ totaliza 645, com a média de 81 leitos.

(g) O número de alunos em cada ano varia dentro dos limites extremos de 32 e 600; em 15 escolas encontramos um total de 2.512 estudantes, com a média de 166 por turma.

(h) Quando estudamos a relação entre o número de estudantes e o número de leitos verificamos valôres diversos; assim, na Universidade de Louvain (Bélgica) existem 58 leitos para 400 alunos $(1: 6,6)$, enquanto que na Universidade de Oslo (Noruega) existem 103 leitos para 30 estudantes $(3,5: 1)$.

Na Asia e Austrália - Recebemos informações de 5 escolas da Asia (41. Universidade de Calcutta, fndia; 42. Hadassah University, Israel; 43. University of Tokyo, Japão; 44. Ankara University, Turquia) e de uma da Austrália (45. University of Melbourne). As características do ensino da Neurologia nestas escolas são de tal modo distintas que uma apreciação comparativa seria por demais artificial; faremos, pois, uma análise mais individual de cada escola.

(a) O currículo médio tem a duração de 4 anos em uma (43), de 5 anos em outra (41) e de 6 anos nas outras três. 
(b) O ensino da neuranatomia e da neurofisiologia é feito independentemente da Neurologia e está a cargo dos departamentos de anatomia e fisiologia, respectivamente, nos primeiro e segundo anos do curso.

(c) Existe departamento de Neurologia autônomo em 3 escolas $(41,42,44)$ nas outras duas, a Neurologia é parte do departamento de medicina interna.

(d) A existência de 5 faculdades de medicina na Universidade de Calcutá (fndia), faz com que os cursos sejam múltiplos e simultâneos, desenvolvendo-se do $3^{\circ}$ ao $5^{\circ}$ ano do currículo. O departamento de Neurologia é autônomo. Nāo obtivemos maiores informaçōes sôbre o curso.

(e) Na Universidade Hadassah (Israel) o departamento de Neuroolgia é autônomo e o curso é ministrado nos $4^{\circ}$ e $6^{\circ}$ anos; no $4^{\circ}$ ano é dado o curso de semiologia e no $6^{\circ}$ ano são ministradas 40 aulas teóricas com estágios em enfermarias e em ambulatório durante um mês; simultâneamente, os estudantes participam de reuniões anátomo-clínicas, neurorradiológicas e neurocirúrgicas, uma vez por semana.

( $f$ ) Na Universidade de Tóquio (Japão) a Neurologia é ensinada como parte da Clinica Médica, do mesmo modo que a Psiquiatria, e não apresenta programação própria, as aulas sendo ministradas quando a seqüência clínica as exige. Tais aulas correspondem a um sétimo do tempo dedicado ao ensino pelo departamento de Clinica Médica, durante os $2^{\circ}, 3^{\circ}$ e $4^{\circ}$ anos: no $2^{\circ}$ ano são ministradas aulas de semiologia e, nos $3^{\circ}$ e $4^{\circ}$ anos, aulas teóricas com apresentação de casos clinicos, estágio em enfermarias e atendimento em ambulatório.

(g) Na Universidade de Ankara (Turquia) o curso de Neurologia desenvolve-se nos $3^{\circ}$ e $4^{\circ}$ anos; as aulas teóricas, em número de 26 , são ministradas no 3o ano; o curso prático é feito em regime de dedicação integral, durante um mês, no $4^{\circ}$ ano. Os estudantes freqüentam as enfermarias, comparecem uma hora por dia ao ambulatório e participam de duas discussões clínico-patológicas.

(h) Na Universidade de Melbourne (Austrália) a Neurologia e demais especialidades são ensinadas juntamente com a clínica mélica, cirurgia, pediatria e ginecologia e obstetricia, sem que haja programas especiais. Não obtivemos maiores informações sôbre a organização dos cursos.

(i) O número de alunos varia de $80(42,43)$ a 160 (45).

(j) Não obtivemos informaçōes sôbre o número de leitos e sôbre a constituição do corpo docente destas escolas.

No Brasil - A situação atual do ensino da Neurologia não poderá ser expressa com fidelidade neste relatório, desde que obtivemos dados referentes a apenas 6 escolas (46. Faculdade de Medicina de Maceió, Alagoas; 47. Faculdade de Medicina da Univ. da Bahia; 48. Faculdade de Medicina da Univ. de São Paulo; 49. Escola Paulista de Medicina; 50. Faculdade de Medicina da Pontificia Univ. Católica, Sorocaba, São Paulo; 51. Faculdade de Medicina de Ribeirão Prêto da Univ. de São Paulo):

(a) A duração do curso médico é de 6 anos em tôdas estas escolas.

(b) O ensino da neuranatomia é feito independentemente da Neurologia em 5 das escolas; em uma (50) existe a integração dos cursos, sendo que as aulas de neuranatomia estão a cargo de docentes do departamento de Neurologia. O ensina da neurofisiologia não tem relação com o curso de Neurologia nas 6 escolas. Por outro lado, em $2(50,51)$ o curso de neuropatologia é integrado ao curso de Neurologia.

(c) Em 4 escolas $(47,49,50,51)$ são realizados cursos de semiologia do sistema nervoso para os alunos do $3^{\circ}$ ano, as aulas sendo ministradas por neurologistas. Tais cursos têm duração variável e são constituidos principalmente por aulas e demonstrações práticas, utilizando doentes hospitalizados e pacientes de ambulatório.

(d) O curso de clínica neurológica desenvolve-se no $5^{\circ}$ ano em tôdas as escolas e os programas incluem aulas teóricas e práticas. As teóricas compreendem problemas de fisiopatologia do sistema nervoso, o estudo das grandes sin- 
dromes neurológicas e a exposição das principais entidades clínicas neurológicas. A duração do curso varia, com limites extremos de 14 e 42 aulas e com média de 30 aulas. O curso prático também tem duração bastante variável, com limites de 14 a 92 horas e com média de 50 horas. Para as aulas práticas são utilizados indiferentemente doentes internados e de ambulatório. Em uma das escolas (51) os alunos do $6^{\circ}$ ano fazem estágio obrigatório no departamento de Neurologia durante quatro semanas, atendendo no ambulatório e participando de reuniōes clínicas e clínico-patológicas. Em 3 escolas $(47,48,51)$ o ensino da neurocirurgia se faz em completa integração com a Neurologia.

(e) Das 6 Faculdades, $4(48,49,50,51)$ mantêm departamentos de Neurologia autônomos; em uma (46) o serviço de Neurologia faz parte do departamento de Clínica Médica; em outra (47) a Neurologia constitui um departamento juntamente com a Psiquiatria e a Medicina legal.

( $f$ ) O nmero de leitos para enfermos neurológicos perfaz o total de 170 , com limites extremos de 8 e 70; tal número deve ser considerado insuficiente, desde que os leitos de uma escola (48) representam $42 \%$ do total.

( $g$ ) O número de alunos por turma em cada escola varia bastante, com iimites de 30 e 90 e média de 60 .

(h) A constituição do corpo docente é muito desigual nas diversas escolas; duas $(48,49)$ possuem 63 elementos docentes, ao passo que as demais 4 totalizam 33 docentes.

o número de docentes trabalhando em tempo integral é muito reduzido: em uma das escolas (48) existem dois docentes em regime de dedicação exclusiva ao ensino e pesquisa e, em outra (51), existem 7 docentes em regime de tempo integral geográfico. Nas demais escolas, todos os membros do corpo docente trabalham em regime de tempo parcial.

Comentários - A Neurologia, antes da segunda guerra mundial, mantinha-se demasiado prêsa a conceitos tradicionais de especialidade dedicada a diagnósticos anátomo-clínicos muito precisos e prevalentemente ao estudo de afecções raras; assim, um grande número de doenças neurológicas dependentes de processos tóxicos infecciosos, traumáticos e, mesmo, tumores foi passando progressivamente para as mãos de outros especialistas. Nos últimos 25 anos, com o grande impulso da medicina geral, também se observou o desenvolvimento de uma nova Neurologia que encara todos os aspectos neurológicos das moléstias internas; tal empreendimento foi realizado diante da necessidade imperiosa de recuperação de milhares de indivíduos afetados, direta ou indiretamente, pela segunda Guerra mundial. Para isso foram organizadas campanhas educativas, levantados recursos públicos e particulares, conseguida a renovação do ensino da Neurologia nas escolas médicas e criados novos institutos para pesquisas neurológicas.

No currículo de graduação nos Estados Unidos da América do Norte, a Neurologia foi colocada em situação de integração completa com o ensino de tôda a medicina, adquirindo posição axial, pois que o aluno começa a pensar nela através dos conhecimentos ne neuranatomia, neurofisiologia, neurofarmacologia e neuropatologia que recebe nos primeiros anos; toma contato direto com ela logo após, quando recebe ensinamentos de semiologia do sistema nervoso e aprende a raciocinar com ela durante todo o curso clínico, quer em aulas teóricas, quer em aulas práticas junto aos doentes, vindo coroar seus conhecimentos no curso de clínica neurológica.

$\mathrm{Na}$ Europa, os currículos do curso médico são mais longos e a Neurologia ainda não adquiriu a importância que lhe é devida. Não existe, se- 
gundo os dados que conseguimos obter, integração com as ciências básicas. Em alguns países, o ensino da Neurologia continua vinculado ao da Psiquiatria, em outros se dilui dentro da medicina interna. Não existe, aparentemente, estímulo para formação de neurologistas puros, embora a Neurologia cultivada por alguns dos mais eminentes homens de ciência seja de excelente envergadura.

$\mathrm{Na}$ Àsia, com exceção de Israel e Turquia, e na Austrália, o ensino da Neurologia não é particularizado.

No Brasil, foi com grande satisfação que pudemos verificar ser o ensino de Neurologia nas escolas médicas do Estado de São Paulo de organização e nivel comparáveis aos melhores. Esta situação, não nos furtamos de dizer, se deve em grande parte ao impulso que foi dado à Neurologia brasileira por Enjolras Vampré e seus discípulos.

Idéias conclusivas - Do exposto, sugerimos que desta mesa redonda surjam algumas conclusōes que poderão ser adotadas pela Academia Brasileira de Neurologia e sugeridas a tôdas as cátedras de Neurologia do Pais, no sentido de que o ensino do curso médico seja organizado segundo alguns princípios fundamentais. A experiência assim obtida no decorrer dos próximos 4 ou 6 anos poderá constituir motivo para uma nova mesa redonda, no sentido de se aperfeiçoar o ensino; conseqüentemente, poderemos formar médicos com bons conhecimentos dos princípios da clínica neurológica, capazes de maior e melhor atendimento de nossa infeliz população rural, acometida por tão grande número de moléstias endêmicas. Do melhor ensino fatalmente decorrerá, também, o interêsse de maior número de jovens pela Neurologia e ciências afins.

\section{Recomendações:}

1. O ensino da clínica neurológica deverá ser iniciado precocemente no curriculo das escolas médicas, ficando póximo aos cursos das ciências básicas (neuranatomia, neurofisiologia, neurofarmacologia e neuroquímica). Dêste modo, o aluno, ao iniciar o estudo de semiologia geral, aprenderá a semiologia neurológica sob a orientação direta de neurologistas.

2. O ensino da clínica neurológica deverá ser feito no $5 .^{\circ}$ ano, quando o aluno já recebeu os conhecimentos fundamentais da patologia interna.

3. O ensino da clínica neurológica deverá abranger os quadros clínicos e a semiologia das afecções neurocirúrgicas, sendo as aulas ministradas por docentes que delas tenham experiência.

4. Sempre que possivel, o ensino das ciências básicas (neuranatomia, neurofisiologia, neurofarmacologia, neuroquímica) deverá ser feito em íntima integração com o curso de Neurologia.

5. O ensino da neuropatologia deverá ser, pelo menos em parte, ministrado pelos neuropatologistas dentro do curso de clínica neurológica.

6. Estágios obrigatórios em clínica neurológica deverão ser realizados pelos alunos no último ano do curso médico. 


\section{ENSINO DA NEUROLOGIA EM POS-GRADUAÇAO}

Na revisão da literatura sôbre o ensino da Neurologia em pós-graduação encontramos, igualmente, trabalhos resultantes da experiência norte-americana. Em seqüência cronológica, aparece primeiramente a "Conference on Graduate Training in Clinical Neurology", organizada pelo Neurology Graduate Training Grant Committee do National Institute of Neurological Diseases and Blindness, em 1957. Nesta reunião foram salientados alguns pontos de vista fundamentais, como seja a necessidade de trabalho em tempo integral para o candidato, em internato de 3 anos no minimo. Nesse internato, em trabalho programado para cada ano, o candidato aperfeiçoa seus conhecimentos das ciências básicas correlatas à Neurologia; participa ativamente dos trabalhos clínicos e dos exames paraclínicos dos pacientes; assume a responsabilidade de execução dos tratamentos prescritos, observando os efeitos dos medicamentos, as possiviveis intolerâncias e a evolução habitual de cada afecção neurológica. Foi salientada, também, a importância do trabalho em ambulatório; quando bem organizado e integrado com a parte hospitalar de internação e com a de exames subsidiários, o número de pacientes visto pelo médico atendente é muito maior, com grande variedade de síndromes neurológicas; numerosos quadros clínicos só são vistos em ambulatórios e os pacientes podem ser fàcilmente seguidos por longo tempo; os estagiários aprendem a estabelecer a relação médico-doente, como conhecer e procurar resolver os problemas do doente frente à sua doença, sua vida e sua família. No ambulatório não existe aquela separação artificial de responsabilidade entre os mais novos e os de maior graduação no atendimento dos pacientes, cabendo ao estagiário assumir parte desta responsabilidade.

A atenção foi também chamada, nessa reunião, para as vantagens de departamentos de Neurologia autônomos, mas funcionando em intima correlação com os serviços de Neurocirurgia, realizando reuniões conjuntas com os departamentos de Medicina Interna, Pediatria, Oftalmologia, colaborando intimamente com os departamentos de ciências básicas. $O$ aluno e o interno residente estarão muito mais interessados pela clínica neurológica e a compreenderão melhor se estiverem aptos a viver igualmente os conhecimentos básicos de neuranatomia, neurofisiologia e neuropatologia. Da mesma forma, a neurorradiologia e a eletrencefalografia devem estar sob a responsabilidade de neurologistas especialmente treinados; sòmente o neurologista encontra-se em situação de viver os diferentes aspectos de cada caso clínico e, assim, obter dêstes métodos semiológicos o máximo proveito em benefício dos pacientes.

Complementando a revisão bibliográfica relativa à Neurologia norte-americana, vale a pena referir o que diz Baker (1957) sôbre a situação em 1952, quais as providências tomadas para a resolução do problema e quais os resultados conseguidos 4 anos após. Nessa época, aproximadamente 15 milhões de pessoas achavam-se afetadas por distúrbios neurológicos, não sendo computados os portadores de moléstias neurológicas agudas e grande número de indivíduos com complicaçōes neurológicas secundárias a moléstias internas; êste número representava o dôbro daquele de pessoas com afecções cardíacas e câncer. Das 79 escolas médicas do pais, sòmente 15 desenvol- 
viam programa de treinamento em Neurologia, com um total de 90 médicos em estágio de pós-graduação. A falta de interêsse pela Neurologia decorria da deficiência do ensino da especialidade nas diferentes escolas médicas: de 7.500 graduados anualmente, menos de $50 \%$ recebiam ensino de Neurologia ministrado por neurologistas. As conseqüências eram alarmantes: (a) privava a população dos beneficios de tratamentos adequados, mesmo quando êsses tratamentos eram possiveis; (b) privava a metade dos médicos de adquirir os conhecimentos mínimos da Neurologia, impedindo-os de desenvolver possível interêsse no seu estudo e afastando a oportunidade de muitos dêles para a especialização.

Contra esta situação foram tomadas providências, tanto por parte dos responsáveis pela Neurologia como por iniciativa dos próprios doentes, através de suas instituições de saúde, alarmados que estavam pela precária situação da assistência médica que lhes era oferecida. Assim, foram criados grupos voluntários de assistência, tais como a "American League Against Epilepsy", a "United Cerebral Palsy Association", o "Commitee for Public Understanding of Epilepsy", a "National Multiple Sclerosis Society", a :Muscular Dystrophy Association", a "National Society for Crippled Children and Adults". Foi criado o "National Commitee for Research in Neurological Disorders" e o seu primeiro passo foi solicitar aos poderes públicos as providências para a correção da situação, sendo programado um esquema para o estabelecimento de "grants" para o treinamento de novos especialistas; ulteriormente foi organizado o "National Institute of Neurological Diseases and Blindness". O resultado foi auspicioso: os fundos concedidos pelo Congresso Nacional, que foram de US\$ 36.000 em 1952, passaram a

US\$ 4.150.000 em 1956; os serviços reconhecidos para pós-graduação, que eram inicialmente em número de 9, receberam ajuda para melhorar e ampliar seus programas de estudo e pesquisa, e ascenderam para 45; o número de residentes cresceu de 90 para 200; a expansão da área beneficiada por êsses programas foi geográfica e socialmente significativa.

A idéia fundamental que norteou o "Neurology Graduate Training Grant Committee" foi a de organizar serviços efetivos com pessoal bem treinado e dedicado ao ensino, único meio capaz de prover médicos habilitados para uma assistência adequada aos enfermos neurológicos e também pessoal capacitado para o ensino e a pesquisa, bases imprescindíveis para o desenvolvimento da Neurologia e para o treinamento de número cada vez maior de médicos recém-formados.

Poser (1960) refere que 109 programas de treinamento estavam aprovados e 280 médicos estavam matriculados em cursos de pós-graduação em 1958.

A experiência norte-americana quanto ao ensino de pós-graduação em Neurologia e ao sistema de "grants" oferecidos pelos poderes públicos federais, foi avaliada em inquérito feito entre 89 diretores de programas, pela American Academy of Neurology e pela American Neurological Association em 1962. O resultado dêsse inquérito pode ser assim sumarizado: (a) houve acôrdo em que os serviços de Neurologia devem ser autônomos para que os internos e residentes possam assumir maiores responsabilidades nos 
contatos com os pacientes; êsses serviços necessitam ter recursos próprios ou conexões intimas com outros serviços, para que o interno possa ter treinamento suficiente em clínica e em ciências básicas relacionadas (neuranatomia, neurofisiologia, neurofarmacologia, neuropatologia e neuroquimica) e em eletrencefalografia, neuroftalmologia, neurorradiologia e neurotologia; (b) os candidatos a especialistas em Neurologia devem ter prévio treinamento em Medicina Interna ou Pediatria, conforme se destinem a cuidar de adultos ou crianças; (c) em relação às entidades federais que propiciam fundos para o desenvolvimento de programas, as opiniōes não foram concordes, havendo discordâncias quanto à rigidez dos programas e à ênfase que dão a pesquisas nem sempre de aplicação prática imediata. Alguns propugnaram pela adoção de programas de ensino e de treinamento menos uniformes, permitindo que a sua orientação seja, ao menos parcialmente, decidida pelos próprios educadores, que poderão auscultar as tendências, as iniciativas originais e a própria formação dos educandos; os que pensam assim acreditam que êsse modo de agir permitirá formar maior número de especialistas aptos a atender às necessidades de saúde da população, que é o principal objetivo. Simultâneamente, outra meta de grande alcance deve ser visada, qual seja a formação de médicos para a carreira universitária; o recrutamento deverá ser feito entre aquêles que estão em treinamento, encorajando-os a fazer pesquisas e estudos mais especializados.

Na Alemanha, segundo Scheid (1960), o ensino da Neurologia está ainda muito influenciado por dois problemas antigos e tradicionais da medicina germânica: a tendência para as aulas magistrais e a firme vinculação Neurologia-Psiquiatria.

$\mathrm{Na}$ Inglaterra, os pontos de vista são divergentes. Walshe (1960) é entusiasta da nova clínica neurológica, dinâmica, e propugna para que os neurologistas assumam a liderança dos novos campos de estudo - a neuroquímica, por exemplo - que não podem e não devem ficar nas mãos dos homens de laboratório, pois que só os neurologistas conhecem os problemas da patologia do sistema nervoso. Miller (1961) se mostra algo pessimista em relação à formação de neurologistas em seu país, dada a inexistência de cátedras de Neurologia e em face do currículo demasiado extenso a ser desenvolvido pelos jovens médicos que se candidatam a esta especialidade; além disso, são poucos os serviços de clínica neurológica nos quais podem estagiar. Com surpresa deparamos com a informação de que em todo o país existiam, nessa época, apenas 70 neurologistas.

\section{RESUltadOS DO INQUÉRITO REALIZADO}

Nos Estados Unidos da América do Norte - O presente estudo é baseado nas informações obtidas de 12 escolas médicas norte-americanas $(1,2,3,4,5,7,8,9$, $10,11,12,13)$ :

(a) Cursos de pós-graduação são realizados em 9 escolas $(1,2,3,4,5,7$, $8,9,13)$.

(b) Em 4 destas $(1,4,5,13)$ é exigido um estágio prévio em Medicina Interna, com duração mínima de um ano. 
(c) Os cursos de pós-graduação tém a duração de 3 anos em cada uma destas escolas.

(d) Em tôdas as 9 escolas o curso de pós-graduacão fornece treinamento especial em Neurologia.

(e) Nos programas dêstes cursos estão incluídas diversas especialidades e subespecialidades: existem cursos ou estágios em neuranatomia e neurofisiologia em 7 escolas $(1,3,5,7,9,13)$; de neuropatologia em tôdas; de neuroquímica em $4(4,8,9,13)$; de neurofarmacologia em $3(3,5,7)$; de neuroftalmologia em 4 $(1,2,3,4)$; de neuropediatria em tôdas; de Fisioterapia e Reabilitação em 4 $(1,2,7,13)$; de Ortopedia em $2(1,8)$; de Genética em 1 (9); de Psiquiatria em $6(1,2,3,8,9,13)$; de neurocirurgia em tôdas.

(f) Em todos os cursos de pós-graduação estão previstos estágios nos serviço de neurorradiologia, eletrencefalografia e liquido cefalorraqueano.

Na Europa - Obtivemos informações de 18 escolas européias (21 a 38):

(a) Cursos de pós-graduação são feitos em 17 escolas.

(b) Dentre estas, $10(24,25,26,27,31,32,33,34,35,37)$ exigem um estágio prévio em Medicina Interna, por um período minimo de seis meses.

(c) Os cursos de pós-graduação têm duração variável; em 2 escolas $(23,37)$ é de 2 anos; em $12(21,22,24,25,26,27,29,30,31,32,33,35)$ é de 3 anos; em $2(34,36)$ é de 4 anos.

(d) As exigências para a concessão do certificado de pós-graduação sāo diversas; assim, 2 escolas $(29,30)$ prevêm a defesa de tese ao fim do curso; 2 (21, 37) realizam um exame final sôbre as matérias ensinadas no curso; 3 (26, 27, 31) requerem um ano adicional de Psiquiatria a fím de permitir a obtenção do título de pós-graduado em Neuro-Psiquiatria; em uma (33) o curso de pósgraduação completo é de 6 anos, sendo o primeiro nivel correspondente aos cursos das demais escolas, com duração de 3 anos e, o segundo, de estudos especializados durante mais 3 anos.

(e) Em 11 escolas o curso de pós-graduação se refere apenas à Neurologia e em $6(21,29,30,32,35,36)$ o titulo é para Neuro-Psiquiatria.

(f) No desenvolvimento dos cursos, o médico deve, obrigatơriamente, passar por diversos serviços. $\operatorname{Em} 2$ escolas $(23,25)$ são exigidos estágios em neuranatomia e neurofisiologia; em uma (23) em Bioquimica; em uma (25) em Farmacologia; em 2 (21, 23) em neuropatologia; em uma (23) em Psicologia, Otologia e Oftalmologia; em $8(21,23,26,27,31,32,33,34)$ em Psiquiatria; em 9 (23, $24,26,27,28,29,32,33,35)$ em Neurocirurgia.

Na Asia e Austrália - Os dados foram obtidos de 5 escolas médicas:

(a) Em $3(41,42,44)$ os cursos de pós-graduação são regulares.

(b) Em uma (44) é exigido o estágio prévio em Medicina Interna, em outra (42) isso não é exigido e na terceira (41) o treinamento é realizado dentro do curso de pós-graduação em Medicina Interna.

(c) Nas 3 escolas a duração total dêsse curso é de 4 anos.

(d) Duas escolas $(42,44)$ fornecem o título de pós-graduado em Neurologia e uma (41) em Medicina Interna.

(e) As exigências quanto a estágios em outros serviços dizem respeito apenas à neuranatomia e neurofisiologia (42) e à Psiquiatria (42, 44).

No Brasil - Das 6 escolas brasileỉras incluidas neste relatório, apenas três (48, 49, 51) mantém cursos regulares de pós-graduação. Em tôdas é necessário um estágio prévio em Clínica Médica. Os cursos têm a duração de 2 anos, mas os programas para treinamento variam de uma para outra. Contudo incluem o ensino de ciências básicas (neuranatomia e neurofisiologia), neuropatologia, neuropediatria e neurocirurgia, além de estágios nos diferentes serviços neurológicos, como laboratório de líquido cefalorraqueano, neurorradiologia e eletrencefalografia. 
Comentários - Do que nos foi possivel analisar, verificamos que tanto nos Estados Unidos da América do Norte como na Europa, os estágios de treinamento intensivo ou os cursos de pós-graduação são imprescindiveis para a formação de especialistas em Neurologia.

Nos Estados Unidos, depois de uma experiência bem dirigida nestes últimos 25 anos, já existe consenso uniforme a respeito do currículo necessário a ser desenvolvido em 3 anos de trabalho integral, tal como foi sumarizado na reunião conjunta da American Academy ou Neurology e da American Neurological Association, em 1962.

$\mathrm{Na}$ Europa, ainda são bastante heterogêneos os roteiros seguidos e mesmo os fins colimados, isto é, utilizam-se de cursos de pós-graduação diversos; enquanto em alguns países se formam neurologistas puros, em outros a finalidade é a diplomação de especialistas em Neuro-Psiquiatria.

No Brasil, as tentativas de sistematização da residência ainda estão em fase embrionária, embora os primeiros passos já tenham sido dados. A Associação Paulista de Medicina aprovou os requisitos mínimos para um serviço especializado e exige que o candidato ao título de especialista faça prova de ter estagiado, no mínimo durante dois anos, em um dêstes serviços. A Sociedade Brasileira de Neurocirurgia, em convênio com a Associação Médica Brasileira, já estabeleceu as condições indispensáveis para os estágios de pós-graduação. Por isso, pensamos que desta mesa redonda possam resultar algumas normas gerais que venham a ser sugeridas pela Academia Brasileira de Neurologia e adotadas pelos vários departamentos e institutos de Neurologia, com a finalidade de oferecer melhores oportunidades para a formação de neurologistas.

\section{Recomendações :}

1. A Academia Brasileira de Neurologia ( $A B N$ ) organizará, dentro das normas de seus estatutos, uma comissão que se incumbirá de dar parecer sôbre os serviços para o ensino de pós-graduação em Neurologia, que se organizará dentro de requisitos mínimos por ela estabelecidos.

2. A ABN solicitará ao Ministério de Educação e Cultura a concessão de bôlsas de estudo para os candidatos por ela selecionados para estagiar por dois anos em um dos serviços que vierem a ser qualificados.

3. A comissão indicada elaborará um regulamento do qual constarão os requisitos mínimos que o serviço a ser qualificado deve apresentar, assim como as normas que nortearão o exame do curriculo e das credenciais pessoais dos candidatos a essas bôlsas.

4. Esta comissão poderá, imediatamente, dentro dessas normas, dar início ao reconhecimento provisório dos serviços e à aprovação de candidatos a bôlsas. A experiência dos próximos dois anos com a execução dêste programa, ditará as normas finais para a elaboração de um regulamento e para o critério de constituição dessa comissão nos anos subseqüentes; tais normas serão submetidas à próxima Assembléia ordinária da ABN. 


\section{REFERENCIAS}

ARING, C. D. - The place of Neurology in the medical firmament. J. Ass. Am. Med. Coll. 21:220-222, 1946. BAILEY, Pearce - Program for the activation on Neurology under the Veterans Administration. J.A.M.A. 134:1283, 1947. BAILEY, Pearce - The present outlook for Neurology in the United States; a factual evaluation. J. Ass. Am. Med. Coll. 24:214-228, 1949. BAILEY, Percival - The present state of American neurology. J. Neuropath. Exper. Neurol. 1:111-117, 1942. BAILEY, Percival - The practice of Neurology in the United States of America. J. Ass. Am. Med. Coll. 21:281-292, 1946. BERMAN, S. - Neurology in South Africa; a short account of its history and present status. World Neurology, 1:348-355, 1960. BUCY, P. C. - Surgical neurology and biology. J.A.M.A. 115:261-263, 1940. BROUWNER, B. - Training of the neurologist. Arch. Neurol. \& Psychiat. 29:624633, 1933. CONFERENCE ON TRAINING IN CLINICAL NEUROLOGY - Sob os auspicios do National Advisory Neurological Diseases and Blindness Council e do National Institute of Neurological Diseases and Blindness. Neurology, supj., 1956. CONFERENCE ON TRAINING IN CLINICAL NEUROLOGY - idem, Neurology, supl., 1957. DE JONG, R. - Undergraduate education in Neurology. J. Med. Educ. 26:149-199, 1951. LHERMITTE, J. - Training of the neurologist. Arch. Neurol. \& Psychiat, 30:1111-1126, 1933. MACLEY, R. P. - Comentários na 97: sessão da American Medical Association. J.A.M.A. 133:512, 1947. MILLER, H. The background of contemporary Neurology in Great Britain. World Neurology, 2:322-330, 1962. MONRAD-KROHN, G. H. - Neurology at the crossroads. Neurology, 8:80-81, 1958. NIELSEN, J. M. - Comentárió na 97 sessão da American Medical Association, J.A.M.A. 133:512, 1947. POSER, C. - Undergraduate atitudes toward the specialty of Neurology. Neurology, 9:682-688, 1959. POSER, C. - The specialty of Neurology: role and scope of neurologic practice in the United States. J.-Lancet, 80:93-98, 1960. POSER, C. - Trends in neurological training and education. Clinical Neurology, 1:26-35, 1960. PENFIELD, W. - Training of a neurologist. Arch. Neurol. \& Psychiat. 31:842-844, 1934. POLLOCK, L. J. Discussão sôbre o ensino da Neurologia. J. Ass. Am. Med. Coll. 24:142-149, 1949. RAMSAY-HUNT, J. - The demand of neuropsychiatry and the training of the neuropsychiatrist. Arch. Neurol. \& Psychiat. 31:1078-1094, 1934. REPORT ON POSTGRADUATE EDUCATION - American Neurological Association and American Academy of Neurology Joint Committee. Arch. Neurol. 6:423-427, 1962. RILEY, H. A. - Training of the neurologist. Arch. Neurol. \& Psychiat. 29:862-871, 1933. RILEY, H. A. - The status of Neurology in the United States. J. Nerv. \& Ment. Dis. 106:262, 1947. SCHALLER, W. F. - Comentários na 97 sessão da American Medical Association. J.A.M.A. 133:512, 1947. SCHEID, W. - Neurologic education and training in West Germany. World Neurology, 1:286-293, 196. TRAINING PROGRAM IN PEDIATRIC NEUROLOGY - American Board of Pediatric Neurology. Neurology, 11:269, 1961. VIETS, R. H. - Neurology past and present. J.A. M.A. 101:399-402, 1937. WALSHE, F. M. R. - Training of the neurologist. Arch. Neurol. \& Psychiat. 29:368-382, 1933. WALSHE, F. M. R. - The present and future of Neurology. Arch. Neurol. 2:93-98, 1960. WALSHE, F. M. R. - The basic sciences of neurologic medicine reconsidered. World Neurology, 1:189-198, 1960. WILSON, G. \& RUPP, C. - Present trends in the practice of Neurology. J.A.M.A. 133: 509,1947 